\title{
Microwave-assisted synthesis of platinum nanoparticles and their catalytic degradation of methyl violet in aqueous solution
}

\author{
Jolly Pal • Manas Kanti Deb • Dhananjay Kumar Deshmukh • \\ Bhupendra Kumar Sen
}

Received: 12 September 2012/ Accepted: 14 October 2012/Published online: 30 October 2012

(C) The Author(s) 2012. This article is published with open access at Springerlink.com

\begin{abstract}
A green synthesis of polyvinylpyrrolidone stabilized platinum nanoparticles (PtNPs) has been done by microwave irradiation in the presence of glucose. The formation process of the PtNPs is pursued by UV-visible spectroscopy. The morphology of the PtNPs was characterized by transmission electron microscopy and X-ray diffraction techniques. Catalytic activity of the above PtNPs has been substantiated through photodecolorization of aqueous methyl violet solution.
\end{abstract}

Keywords Green synthesis - Platinum nanoparticles · Catalyst - Dye

\section{Introduction}

Organic dyes are an important class of materials widely used in textile and many other industries, while the hazardous effects of organic dyes in waste water have been a major concern. Methyl violet (MV) is chosen in this study because of its broad applications in textiles, paints and printing inks manufacturing (Mittal et al. 2008). MV is known to give blue shades to dyed materials. In biomedical fields, MV is the active ingredient in gram's biological stain for bacteria classification (Lillie and Conn 1977). Sometimes, it can be used as a moderate-class disinfectant, but found to be very poisonous to most animals. Inhalation of MV may also cause irritation to respiratory tract, whereas ingestion causes

J. Pal · M. K. Deb $(\bowtie) \cdot$ D. K. Deshmukh · B. K. Sen

School of Studies in Chemistry, Pt. Ravishankar Shukla

University, Raipur 492 010, Chhattisgarh, India

e-mail: debmanas@yahoo.com

D. K. Deshmukh

e-mail: dhananjaychem@yahoo.in irritation to gastrointestinal tract (Mittal et al. 2008). The molecular structure of MV is shown in Fig. 1. Conventional treatment methods such as adsorption are often inadequate and inappropriate for removing large amounts of organic dyes from waste water streams; it is also noteworthy that adsorption is a non-destructive method, which simply transfers dyes from one phase or substance to another (Pal and Deb 2012a; Bahgat et al. 2012). In contrast, the treatment method of photo-catalytic degradation has the capability of converting dye molecules into non-toxic compounds. In last decade, photocatalytic degradation using metal nanoparticles has been shown to be effective for destruction of pollutants. Several nanoparticles such as silver, gold, palladium and platinum have been used for photocatalytic destruction of organic pollutants in waste water (Zhang et al. 2004). The increasingly demanding request for new catalysts in terms of recovery, regeneration and reuse has attracted the attention of a significant part of the scientific community (Zhao and Crooks 1999). In this context, nanosized catalysts have recently become a hot topic of interest because of their high surface area that results in outstanding activity (Jiang and Gao 2006; Korneva et al. 2005). As particle size decreases by reaching nanodimension, gradual transformation, from the bulk in the solid-state to the molecular level occurs (Drechsler et al. 2004). By tailoring the size and shape of metal nanoparticles, one can alter and enhance their intrinsic properties for diverse applications. The preparation of metal nanoparticles is usually based on the reduction of a metal salt in the presence of a reducing agent and a stabilizer (Kannan et al. 2012; Nafees et al. 2012; Pal and Deb 2012a, b, c; Karuppuchamy et al. 2012).

Platinum nanoparticles (PtNPs) with high surface to volume ratio are preferred to achieve a reliable catalytic performance and to increase the efficiency. PtNPs preparation methods involve the reduction of Pt ions into NPs in

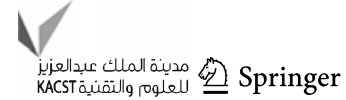




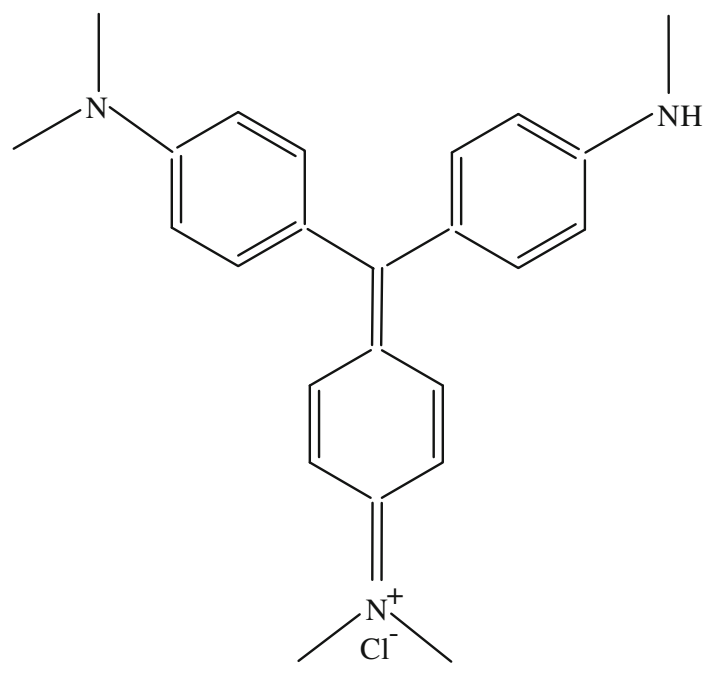

Fig. 1 Chemical structure of methyl violet (MV)

protective media to prevent the metal NPs from aggregating. Water soluble polymers such as poly(vinyl alcohol) (Luo and Sun 2007) and PVP (Pal and Deb 2012b; Pal et al. 2009) have been widely used as protective media for colloidal dispersions. Stabilizers play an important role in controlling the formation of NPs as well as their dispersion stability. On the other hand, the presence of too strong capping agent on the NP surface can limit the particles catalytic activity. Microwaves are electromagnetic waves. Microwave heating is well known in the food industry, and of late has found a number of applications in chemistry, especially in organic chemistry. It is also being used for the development of different materials. In microwave application, heating is caused by the interaction of the permanent dipole moment of the molecule with the high frequency electromagnetic radiation. Also, heating is not only quick but also uniformly spread through the entire bulk of the reaction mixture. This may result in narrow distribution of particle sizes.

We present here a simple, clean and efficient route for preparing PtNPs. PtNPs were prepared by a microwave irradiation procedure. The UV-visible spectra results in the conversion of $\mathrm{Pt}^{4+}$ to $\mathrm{Pt}^{0} \mathrm{NPs}$. Our research shows that this process is a good method to prepare small PtNPs with narrow particle size distribution. We have also reported here the catalytic behaviour of PtNPs from the effective photodecolorization of MV as a model system.

\section{Experimental section}

\section{Materials}

All aqueous solutions were prepared with triple distilled water. Platinum chloride $\left(\mathrm{H}_{2} \mathrm{PtCl}_{6}\right)$ was obtained from Merck, India. Glucose was purchased from Molychem.
PVP and MV were procured from Himedia. All chemicals were used as received without further purification.

Apparatus

Glasswares were cleaned with ultrasonic cleaning bath, Spectra Lab India, model UCB-40 using mild detergent, and after proper washing rinsed with ultrapure water. A Samsung CE2877 domestic microwave oven $(850 \mathrm{~W})$, Samsung India Electronics Ltd. New Delhi, India was employed for irradiating solutions. Absorption spectra were recorded in a Varian Carry $50 \mathrm{UV}$-visible spectrophotometer equipped with a peltier temperature controller unit. The particle size and morphology of the NPs were characterized by Morgagni 268D TEM operating at $80 \mathrm{~KB}$ (Mega view III Camera CCD) at the All India Institute of Medical Sciences (AIIMS), New Delhi. For homogenous stirring of reaction mixture, 5 MLH magnetic stirrer, Remi Equipments Pvt. Ltd., India was used for NPs preparation. The XRD measurements were carried out using Bruker D8 Advance X-ray diffractometer at UGC-DAE Consortium for Scientific Research INDORE-CENTRE. The X-rays were produced using a sealed tube and the wavelength of $\mathrm{X}$-ray was $0.154 \mathrm{~nm}$ (Cu K-alpha). The X-rays were detected using a fast counting detector based on silicon strip technology (Bruker-LynxEye detector).

\section{Preparation of PtNPs}

In a typical synthesis, $10 \mathrm{ml}$ of an aqueous solution of $\mathrm{H}_{2} \mathrm{PtCl}_{6}(0.0005 \mathrm{~mol} / \mathrm{L})$ was mixed with $2 \mathrm{ml}$ of an aqueous solution of glucose $(0.5 \mathrm{~mol} / \mathrm{L})$ and $0.1 \mathrm{ml}$ of $1 \%$ PVP (w/v) in a $50 \mathrm{ml}$ Pyrex flask to obtain a homogeneous reaction mixture. Then the vial was placed on the turntable of the microwave oven. The mixture was irradiated at a power of 450 watt for a total of 3 min duration. However, the above irradiation process was carried out discontinuously in $30 \mathrm{~s}$ instalments to prevent an increase of pressure. After complete irradiation, appearance of a dark brown colour indicates the formation of PtNPs. The above prepared PtNPs was cooled to room temperature for characterization.

Photocatalytic activity

The photocatalytic degradation studies were carried out with use of UV-radiation. The mixture was irradiated with $15 \mathrm{~W} \mathrm{Hg}$ Philip UV lamp inside the photo-reactor. A magnetic stirrer was used during photocatalysis for good mixing of the photocatalysts in the solution. The photocatalytic decomposition of MV on the PtNPs was examined at a wavelength of maximum absorbance $\left(\lambda_{\max }\right)$, that is, at $580 \mathrm{~nm}$ by optical absorption spectroscopy. Typically 
$0.1 \mathrm{ml} \mathrm{PtNPs}$ were added to $20 \mathrm{ml}$ of aqueous solution of MV (10 mg/L) in a $100 \mathrm{ml}$ beaker.

\section{Results and discussion}

Formation of PtNPs

Figure 2a shows the TEM image for the formation of nearly spherical and homogeneous distribution of the synthesized PtNPs. Figure $2 b$ shows the corresponding particles size distribution. The size distribution histogram reveals that PtNPs range from 5 to $10 \mathrm{~nm}$ in size. Approximately $50 \%$ of these nanoparticles consist of particles with $6 \mathrm{~nm}, 30 \%$ particles with $7 \mathrm{~nm}$ and $20 \%$ particles with $9 \mathrm{~nm}$ size diameter. It may be noted that all these particles are well separated from each other. Figure 3 a shows a typical absorption spectrum of $\mathrm{H}_{2} \mathrm{PtCl}_{6}$ in aqueous solution, which displays a strong absorption band in $250 \mathrm{~nm}$. After mixing with glucose and PVP in $\mathrm{H}_{2} \mathrm{PtCl}_{6}$ as shown in Fig. 3b, only 3 min of irradiation the peak at $250 \mathrm{~nm}$ totally disappears. We found that the color of the solution changed from yellow to dark brown.

The structure of the prepared particle is characterized by X-ray diffraction (XRD) as shown in Fig. 4. The average

(a)

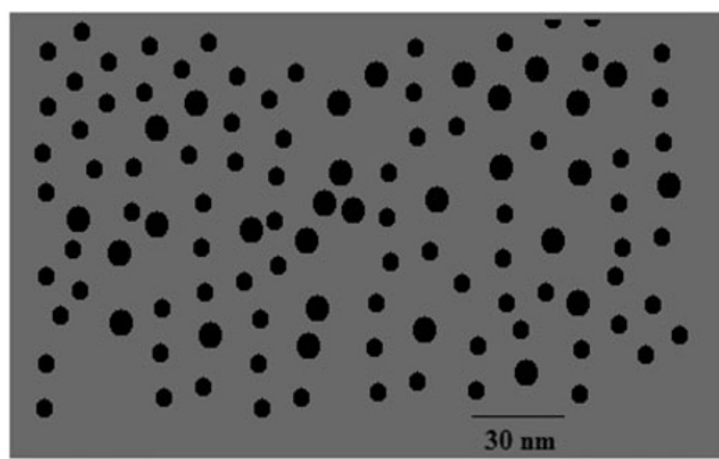

(b)

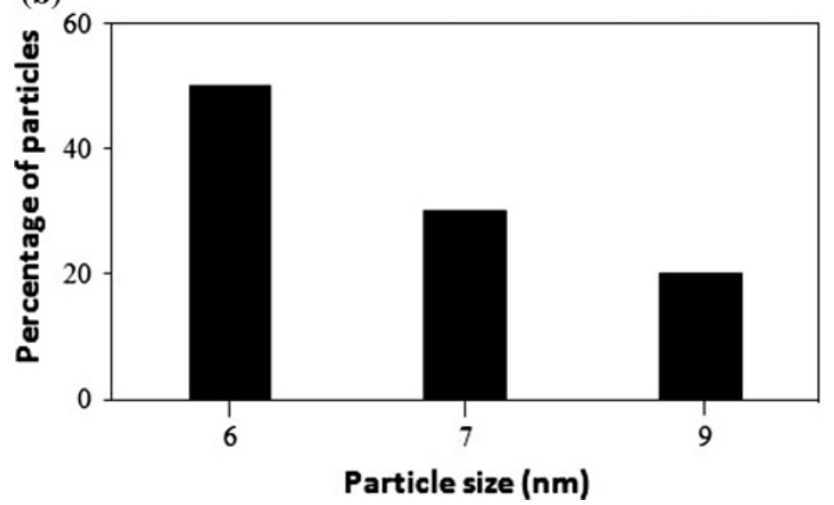

Fig. 2 a TEM image of PtNPs. b Size distribution of the PtNPs synthesized under optimum experimental conditions

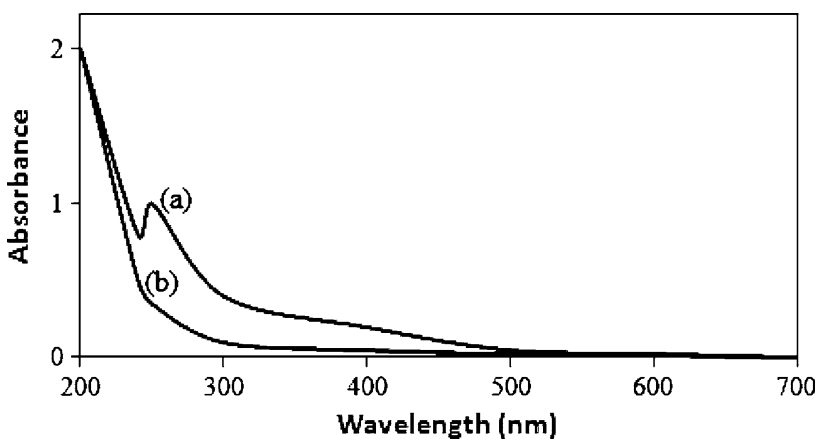

Fig. 3 UV-visible spectra of PtNPs

size of the particles can be derived from the peak width using the Scherrer equation:

$d=\frac{0.9 \lambda}{B \cos \theta}$

where $d$ corresponds to the particle size, $\lambda$ is the $\mathrm{X}$-ray wavelength, $\theta$ is the Bragg's angle and $B$ corresponds to the full width at half maximum (fwhm) of the peak under consideration. At angle $2 \theta$ is $40.66,46.02$ and 69.54 and the corresponding particles size is $6.28,6.41$ and $7.30 \mathrm{~nm}$, respectively. Thus, the PtNPs mean size is estimated to be $7 \mathrm{~nm}$.

Photodegradation of MV

To study the photocatalytic activity of the PtNPs, MV was chosen as a model compound that eventually photodecolorized under UV lamp. To study the photodegradation process, aqueous solution of MV was employed along with PVP-stabilized PtNPs for UV irradiation. Process of MV degradation was monitored by the decrease in absorbance of the peak due to MV at $580 \mathrm{~nm}$. In Fig. 5, the absorption spectra of successive decolorization of the MV is shown. In the absence of PtNPs under the same experimental condition, a slow rate of phorodecolorization was observed, as shown in Fig. 6, in the experimental time scale. Figure 7

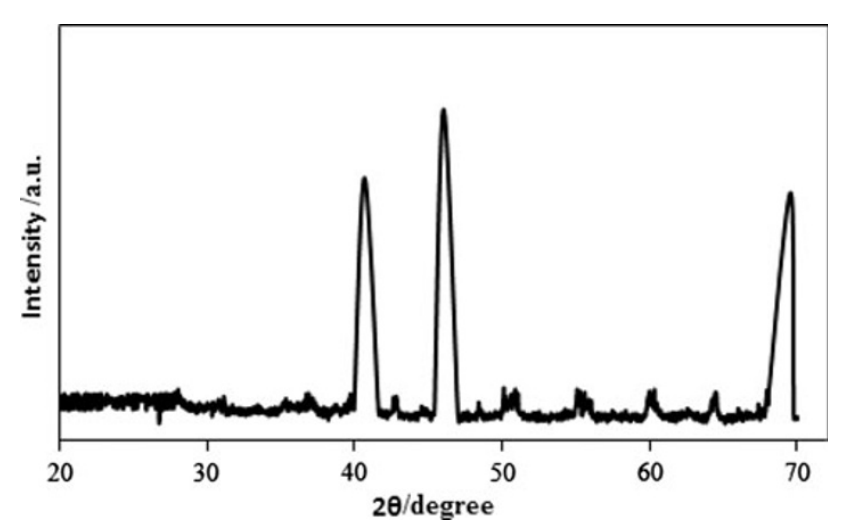

Fig. 4 XRD diffraction pattern for PtNPs 


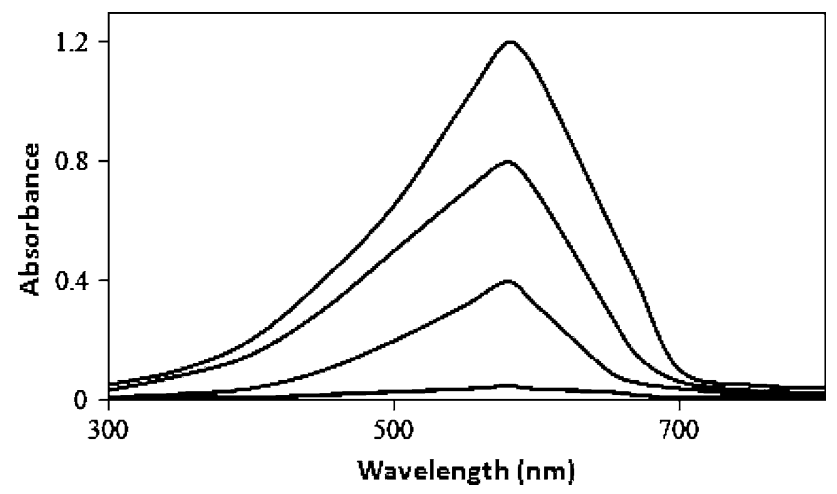

Fig. 5 UV-visible spectra for photodegradation of MV in aqueous solution. The time interval between successive measurements are $5 \mathrm{~min}$

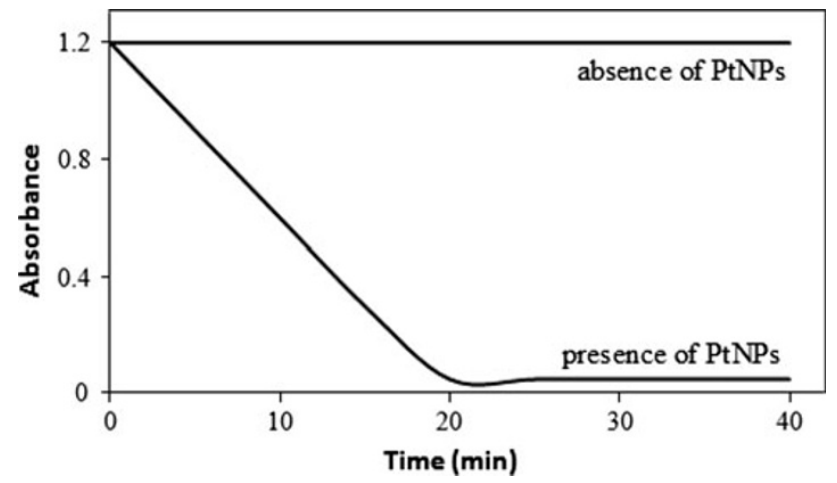

Fig. 6 Absorbance as a function of time in absence and presence of PtNPs

shows the color of MV before and after degradation. It is therefore, obvious that PtNPs catalyses the reaction to a great extent. PtNPs help in photodegradation of MV under UV lamp.

\section{Conclusions}

The characteristic catalytic behaviour of PtNPs is established by studying the decolorization of MV in the presence of UV lamp. In this study, we have demonstrated that monodisperse PtNPs can be synthesized in a glucose and PVP aqueous solution by a microwave irradiation method. The results obtained from UV-visible spectroscopy and TEM clearly demonstrated the reduction of $\mathrm{H}_{2} \mathrm{PtCl}_{6}$. The XRD technique showed the presence of PtNPs with an average size of $7 \mathrm{~nm}$. In conclusion, the microwave irradiation method is simple, versatile and rapid for green synthesis of PtNPs. The important advantage of microwave dielectric heating over convective heating is that the reactants can be added at room temperature or slightly higher temperatures without the need for high temperature

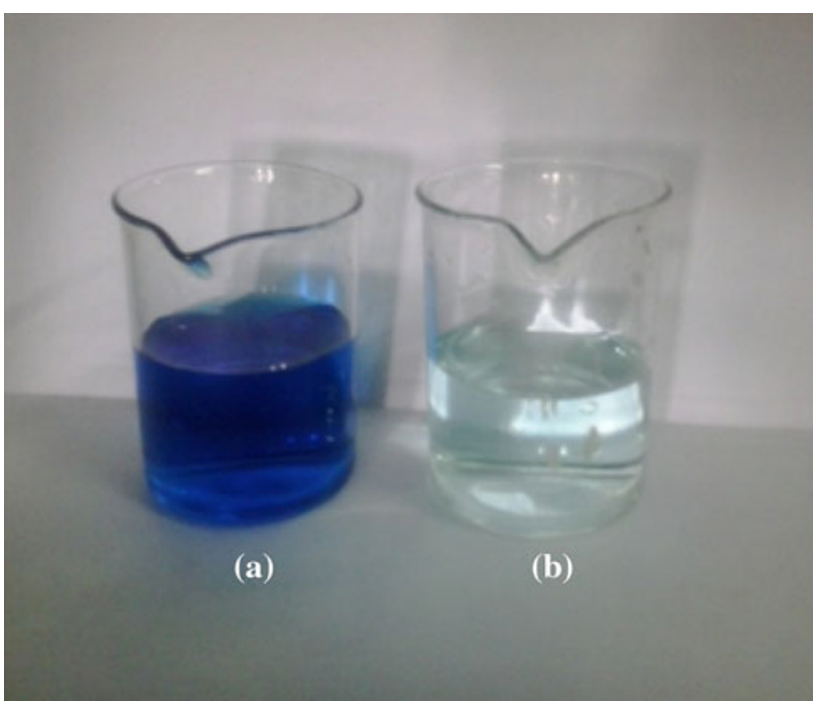

Fig. 7 Colour of MV a before and $\mathbf{b}$ after degradation

injection. The characteristic catalytic behaviour of PtNPs is established by studying the decolorization of MV in the presence of UV irradiation. It has been authenticated from the study that nanoparticles have a tremendous influence on the reaction. The method could be an efficient, highly safe and cost-effective way for the removal of MV from aqueous streams.

Acknowledgments The authors are thankful to the Head, School of Studies in Chemistry, Pt. Ravishankar Shukla University, Raipur, India for providing laboratory facilities. Authors are also thankful to Department of Anatomy, All India Institute of Medical Sciences (AIIMS), New Delhi for providing TEM photographs. The authors wish to thank UGC-DAE Consortium for Scientific Research Indore centre for the XRD analysis. The authors are also thankful to the anonymous reviewers for their constructive comments and suggestions.

Open Access This article is distributed under the terms of the Creative Commons Attribution License which permits any use, distribution, and reproduction in any medium, provided the original author(s) and the source are credited.

\section{References}

Bahgat M, Farghali A, Rouby W, Khedr M, Ahmed M (2012) Adsorption of methyl green dye onto multi-walled carbon nanotubes decorated with $\mathrm{Ni}$ nanoferrite. Appl Nanosci. doi: 10.1007/s13204-012-0127-3

Drechsler U, Erdogan B, Rotello VM (2004) Nanoparticles: scaffolds for molecular receptors. Chem Eur J 10:5570-5579

Jiang Y, Gao Q (2006) Heterogeneous hydrogenation catalyses over recyclable $\mathrm{pd}(0)$ nanoparticle catalysts stabilized by PAMAMSBA-15 organic-inorganic hybrid composites. J Am Chem Soc 128:716-717

Kannan R, Arumugam R, Ramya D, Manivannan K, Anantharaman P (2012) Green synthesis of silver nanoparticles using marine macroalga chaetomorpha linum. Appl Nanosci. doi:10.1007/ s13204-012-0125-5 
Karuppuchamy S, Andou Y, Endo T (2012) Preparation of nanostructured $\mathrm{TiO}_{2}$ photoelectrode for flexible dye-sensitized solar cell applications. Appl Nanosci. doi:10.1007/s13204-012-0140-6

Korneva G, Ye H, Gogtsi Y, Halverson D, Friedman G, Bradley JC, Kornev KG (2005) Carbon nanotubes loaded with magnetic particles. Nano Lett 5:879-884

Lillie RD, Conn HJ (1977) Biological stains: a handbook on the nature and uses of the dyes employed in the biological laboratory. Williams and Wilkins, Baltimore

Luo YL, Sun XP (2007) One-step preparation of poly(vinyl alcohol)protected Pt nanoparticles through a heat-treatment method. Mater Lett 61:2015-2017

Mittal A, Gajbe V, Mittal J (2008) Removal and recovery of hazardous triphenylmethane dye, methyl violet through adsorption over granulated waste materials. J Hazard Mater 150:364-375

Nafees M, Ali S, Idrees S, Rashid K, Shafique M (2012) A simple microwave assists aqueous route to synthesis $\mathrm{CuS}$ nanoparticles and further aggregation to spherical shape. Appl Nanosci. doi: 10.1007/s13204-012-0113-9
Pal J, Deb MK (2012a) Microwave green synthesis of PVP-stabilised gold nanoparticles and their adsorption behaviour for methyl orange. J Exp Nanosci. doi:10.1080/17458080.2012.667160

Pal J, Deb MK (2012b) Green formation and catalytic activity of palladium nanoparticles on brilliant green in aqueous solution. Indian J Environ Prot 32:574-578

Pal J, Deb MK (2012c) Microwave synthesis of polymer coated silver nanoparticles by glucose as reducing agent. Indian $\mathrm{J}$ Chem Sect A 51:821-824

Pal A, Shah S, Devi S (2009) Microwave-assisted synthesis of silver nanoparticles using ethanol as a reducing agent. Mater Chem Phys 114:530-532

Zhang M, An T, Hu X, Wang C, Sheng G, Fu J (2004) Preparation and photocatalytic properties of a nanometer $\mathrm{ZnO}-\mathrm{SnO}_{2}$ coupled oxide. Appl Catal A 260:215-222

Zhao M, Crooks RM (1999) Homogeneous hydrogenation catalysis with monodisperse, dendrimer-encapsulated Pd and Pt nanoparticles. Angew Chem Int Ed 38:364-366 